\title{
Simulation and analysis of the impact of projected climate change on the spatially distributed waterbalance in Thuringia, Germany
}

\author{
P. Krause and S. Hanisch \\ Department for Geoinformatics, Hydrology and Modelling, Friedrich-Schiller-University, Jena, Germany \\ Received: 21 January 2009 - Revised: 17 March 2009 - Accepted: 28 April 2009 - Published: 11 August 2009
}

\begin{abstract}
The impact of projected climate change on the long-term hydrological balance and seasonal variability in the federal German state of Thuringia was assessed and analysed. For this study projected climate data for the scenarios $\mathrm{A} 2$ and $\mathrm{B} 1$ were used in conjunction with a conceptual hydrological model. The downscaled climate data are based on outputs of the general circulation model ECHAM5 and provide synthetic climate time series for a large number of precipitation and climate stations in Germany for the time period of 1971 to 2100 . These data were used to compute the spatially distributed hydrological quantities, i.e. precipitation, actual evapotranspiration and runoff generation with a conceptual hydrological model. This paper discusses briefly the statistical downscaling method and its validation in Thuringia and includes an overview of the hydrological model. The achieved results show that the projected climate conditions in Thuringia follow the general European climate trends - increased temperature, wetter winters, drier summers. But, in terms of the spatial distribution and interannual variability regional differences occur. The analysis showed that the general increase of the winter precipitation is more distinct in the mid-mountain region and less pronounced in the lowland whereas the decrease of summer precipitation is higher in the lowland and less distinct in the mid-mountains. The actual evapotranspiration showed a statewide increase due to higher temperatures which is largest in the summer period. The resulting runoff generation in winter was found to increase in the mid-mountains and to slightly decrease in the lowland region. In summer and fall a decrease in runoff generation was estimated for the entire area due to lower precipitation and higher evapotranspiration rates. These spatially
\end{abstract}

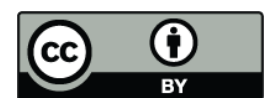

Correspondence to: P. Krause (p.krause@uni-jena.de) differentiated results emphasize the need of high resolution climate input data and distributed modelling for regional impact analyses.

\section{Introduction}

Anthropogenically caused global climate change is exposing the global environment and mankind large challenges which have already been described and investigated in a large number of research projects and publications. The Intergovernmental Panel on Climate Change (IPCC) plays a central role in the coordination and publication of the climate change research. The IPCC Fourth Assessment Report was published in November 2007 (http://www.ipcc.ch/) and comprises the actual progress and findings of the current knowledge about climate change and its global and regional impacts.

The scientific basis for the projection of climate change is provided by simulation results from general circulation models (GCMs). The most common models are coupled atmosphere-ocean general circulation models (AOGCM) which simulate the physical processes in the atmosphere and at the interfaces between atmosphere and oceans or land surface. Such models are used to produce realistic simulations of large-scale patterns of the atmospheric circulation and of other climate variables (van Ulden and van Oldenborgh, 2006). Comparisons of AOGCM model capability to simulate climate conditions over the last century indicated that they are of remarkable quality but that their results still include a considerable amount of uncertainty (e.g. van Ulden and van Oldenborgh, 2006; Randall et al., 2007; Covey et al., 2003; McAvaney et al., 2001).

One AOGCM is the ECHAM5/MPI-OM model that resulted from the coupling of the land-atmosphere-model ECHAM5 with the ocean model MPI-OM both developed by

Published by Copernicus Publications on behalf of the European Geosciences Union. 
the Max-Planck-Institute for Meteorology (Roeckner et al., 2003). ECHAM5 has 31 pressure levels and uses a spatial resolution of 192 circles of longitude and 96 circles of latitude resulting in a grid size of approximately $200 \times 400 \mathrm{~km}$ at the equator. The control run of ECHAM5 over the period of 1961-1990 resulted in an underprediction of up to $1^{\circ} \mathrm{C}$ for the annual mean temperature and an overprediction of the annual mean precipitation of up to $30 \mathrm{~mm}$ in Europe (Randall et al., 2007).

For projections of possible future climate conditions GCMs are typically driven with forcing conditions defined by climate-change scenarios (Ekström et al., 2007). The most common scenarios are B1, A2 and A1B defined in the Special Report on Emissions Scenarios (SRES) prepared by the IPCC (Nakicenovic et al., 2000).

Scenario B1 is characterised by an increased ecological and social awareness and stronger global cooperation of the world's nations. It assumes that new technologies will lead to a more efficient use of natural resources and less consumption of production material. Population growth is assumed to be low and may result in an estimated world population of 7 billion people by $2100 . \mathrm{CO}_{2}$ emissions will rise in the B1 scenario to $9 \mathrm{GtC}$ at 2050 and will then decrease to the amount emitted in 1990.

Scenario A2 is more economically driven than scenario B1 and assumes a larger population growth (15 billion people by 2100), a highly variable regional development and limited technology transfer between the world's nations combined with low initiative to solve global environmental problems together. $\mathrm{A} 2$ assumes that $\mathrm{CO}_{2}$ emissions will rise continuously to $17 \mathrm{Gt} \mathrm{C}$ in 2050 and nearly $30 \mathrm{Gt} \mathrm{C}$ in 2100.

The third scenario, A1B, represents population growth, emission rates and political conditions somewhere in between those of scenarios A2 and B1. The A1B scenario was not considered in this paper because the A2 and B1 scenarios allowed the investigation of the entire range of potential system response to climate change.

The output of GCMs cannot be used directly for regional assessment and impact analysis of climate change because of the relatively coarse spatial resolution. For downscaling GCM output, a wide range of methods has been developed which can be classified into dynamical and statistical approaches (Orlowsky et al., 2007). Dynamical downscaling approaches, often referred to as Regional Climate Models (RCM), simulate the same physical processes as GCMs but on a more refined scale whereby GCM output is used as boundary conditions for the RCMs (Orlowsky et al., 2007). An overview describing the capabilities of a number or RCMs is given in Jacob et al. (2007), Deque et al. (2007) and Christensen et al. (2007b).

According to Wilby and Wigley (1997) and Orlowsky et al. (2007), statistical downscaling approaches can be classified into transfer functions (e.g. Murphy, 1999), weather generators (e.g. Wilks, 1999) and weather type schemes (e.g. Enke and Spekat, 1997). The statistical approaches have in common the use the of GCM output and observed time series as predictors to generate simulated time series for some longer periods of interest (Orlowsky et al., 2007). The WettReg approach (Enke et al., 2005a,b) used in this study is a weather pattern based weather generator which uses ECHAM5 output along with observations from several hundred climate and precipitation stations throughout Germany as input (Enke et al., 2005a).

Bronstert et al. (2006) compared three different regional climate data sets, one from a RCM and two from statistical downscaling approaches for south-western Germany, including the WettReg approach used in this study. They found out that the prognosis of extreme precipitation events and other short-term predictions still retain a high degree of uncertainty but that the data sets are suitable for long-term analysis of hydrological dynamics.

It should be noted that any downscaling approach, statistical or dynamical, that performs well under present climate conditions may not necessarily perform well under future conditions (Murphy, 1999). For instance, the assumptions and statistical constraints derived from present climate and weather patterns used for statistical downscaling may no longer be valid under changed climate conditions. Whereas, RCMs might not be able to reflect potential process changes or changed boundary conditions due to future anthropogenicrelated development of environmental conditions.

The fourth IPCC assessment report states that a likely increase of the annual mean temperature in Europe which will be greater than the global mean. In central Europe precipitation is likely to increase in winter but decrease in summer. The extremes of daily precipitation are very likely to increase in northern Europe and the risk of summer drought is likely to increase in central Europe (Christensen et al., 2007a). Because these projections are based on analysis of coarse-resolution AOGCMs, regional effects, changes and variability cannot be assessed in detail.

Any change in temperature and precipitation will have a direct impact on water quantity, availability and distribution. Because of the importance of hydrology for the eco-system and general human welfare, many research studies have investigated the impact of global climate change on hydrological processes on various scales. These studies used different hydrological models that were driven by the output of different climate models. On a global and continental scale, largescale hydrological models are driven directly with the output of GCMs (e.g. Arnell, 2003; Lehner et al., 2006). On the regional scale most of the time RCMs are used to drive conceptual hydrological models (e.g. Menzel and Bürger, 2002; Kunstmann et al., 2004; Thodsen, 2007; Leander and Buishand, 2007). Most of these studies described problems with the amounts and distribution of precipitation caused by insufficient regional representation by the RCMs.

In this paper, we present a regional assessment study of potential spatial and temporal changes of the seasonal hydrological dynamics for the German state Thuringia. The 
results were derived by the application of the conceptual hydrological model J2000g driven with historical and projected climate data from the statistical downscaling approach WettReg (UBA, 2007a,b; Enke et al., 2005a,b).

A map of the state of Thuringia is shown in Fig. 1. The map shows the elevation above sea level, the location of climate and precipitation stations used in this study and the outlines of twelve catchments used for model calibration and validation mentioned later in the text.

\section{Material and methods}

\subsection{The statistical downscaling approach WettReg}

The WettReg methodology was developed by the companies Meteo-Research and CEC in Potsdam, Germany. WettReg is a weather-pattern statistical downscaling approach that uses circulation patterns and large-scale atmospheric pressure data as input (Enke et al., 2005a,b). WettReg is able to preserve the natural variation of the predicted regional variables; this provides an advantage in comparison to other methods where variability is often reduced (Enke et al., 2005a). The method attempts to reproduce the occurrence frequency of regional weather patterns, which are then used to derive local weather elements, based on statistical information obtained from observed values. Future regional climate is simulated by rearranging recent weather condition periods in such a way that they incorporate circulation changes modelled with CGMs. For this purpose, an objectively-derived circulation pattern classification was developed and used as a downscaling and adjustment tool (Enke et al., 2005b). The frequency distribution of the objective circulation patterns then is adjusted to the one simulated with the CGM for future conditions. Finally, local values for meteorological variables are generated for the new circulation patterns based upon the recombination of observed anomalies. As new extremes due to climate change cannot be provided by the recombination of observed anomalies, these are synthesised using regression functions and distribution adaptations from a combination of different predictors. A much more detailed description of the underlying theory and assumptions is given by Enke et al., 2005a,b.

On behalf of the German Environment Agency (Umweltbundesamt), WettReg was used to create historical and projected climatological time series for 282 climate stations and 1695 precipitation stations in Germany. The projected future climate data were downscaled based on information from ECHAM5 output. Minimum, mean and maximum temperature, precipitation, relative humidity, air pressure, vapour pressure, sunshine duration, cloudiness and wind speed are available in daily resolution for every climate station. The data sets include historical climate data from 1961 to 2000 derived from model control runs of ECHAM5 and projected climate data for 2000 to 2100 for the three SRES scenarios
A2, B1 and A1B. For validation and comparison, observed data from 1971 through 2000 also are included. For every decade, ten different downscaled time series with 7300 time steps ( 2 times 10 years with 360 days) for every weather element are included in the data set. With this large amount of data, the uncertainty of the statistical downscaling approach should be accounted for. It should be noted that every single value (i.e. a weather element for one day) is simply a random value of a well defined statistical field. This precludes the direct use of a single WettReg time series as a driver for any modelling. Moreover, the data should be either averaged beforehand or used to create ensemble predictions in order to provide reliable results.

Validation of the WettReg output was performed for Germany for the hydrological years of the time period 19712000 by the comparison of data derived from the control run of ECHAM5 with observed climate values (UBA, 2007a). The analysis demonstrated that the 30-year mean values of various climate variables were very close to the observed values. The difference of the mean annual temperature from the control runs to the observed values was reported as $-0.1 \mathrm{~K}$ $(+0.1 \mathrm{~K}$ in summer and $-0.4 \mathrm{~K}$ in winter). For some decades, the deviation was sometimes a little bit higher with a maximum value of $-0.7 \mathrm{~K}$ for 1991-2000. The 30 year long-term annual precipitation derived from the control runs indicated a relative deviation of $+0.1 \%$ for summer and $-1.4 \%$ for winter. The deviation of the annual amount was less than $0.05 \%$.

Bronstert et al. (2006) described a validation of WettReg data for the Southwestern German state Baden-Württemberg for the period 1971-2000. This study reported a mean deviation of the long-term average temperature of $-0.04 \mathrm{~K}$ $(+0.1 \mathrm{~K}$ for summer and $-0.17 \mathrm{~K}$ for winter) and a slight overestimation of the mean annual precipitation of $+1.8 \%$ $(+3.0 \%$ for summer and $+0.3 \%$ for winter $)$.

For this study, an additional validation for Thuringia was conducted, based upon the comparison of WettReg temperature and precipitation derived from ECHAM5 control runs and observed values at four climatological stations and two additional precipitation stations (Fig. 1). The stations were selected in such a way that they represent a range of elevations and different geographical regions in Thuringia. The validation was performed using monthly mean values of the air temperature and mean monthly precipitation sums of the period from 1971 through 2000 and showed that WettReg was able to reproduce the measured climatological dynamics quite well. Observed precipitation was matched at all stations sufficiently but it was obvious that WettReg was estimating rainfall for the stations located in lower and medium elevation better than for the two higher elevation stations. Temperature was matched at all stations with only minimal deviations. Based on the good validation results the WettReg data was used without any additional adaptation or correction for this study. 


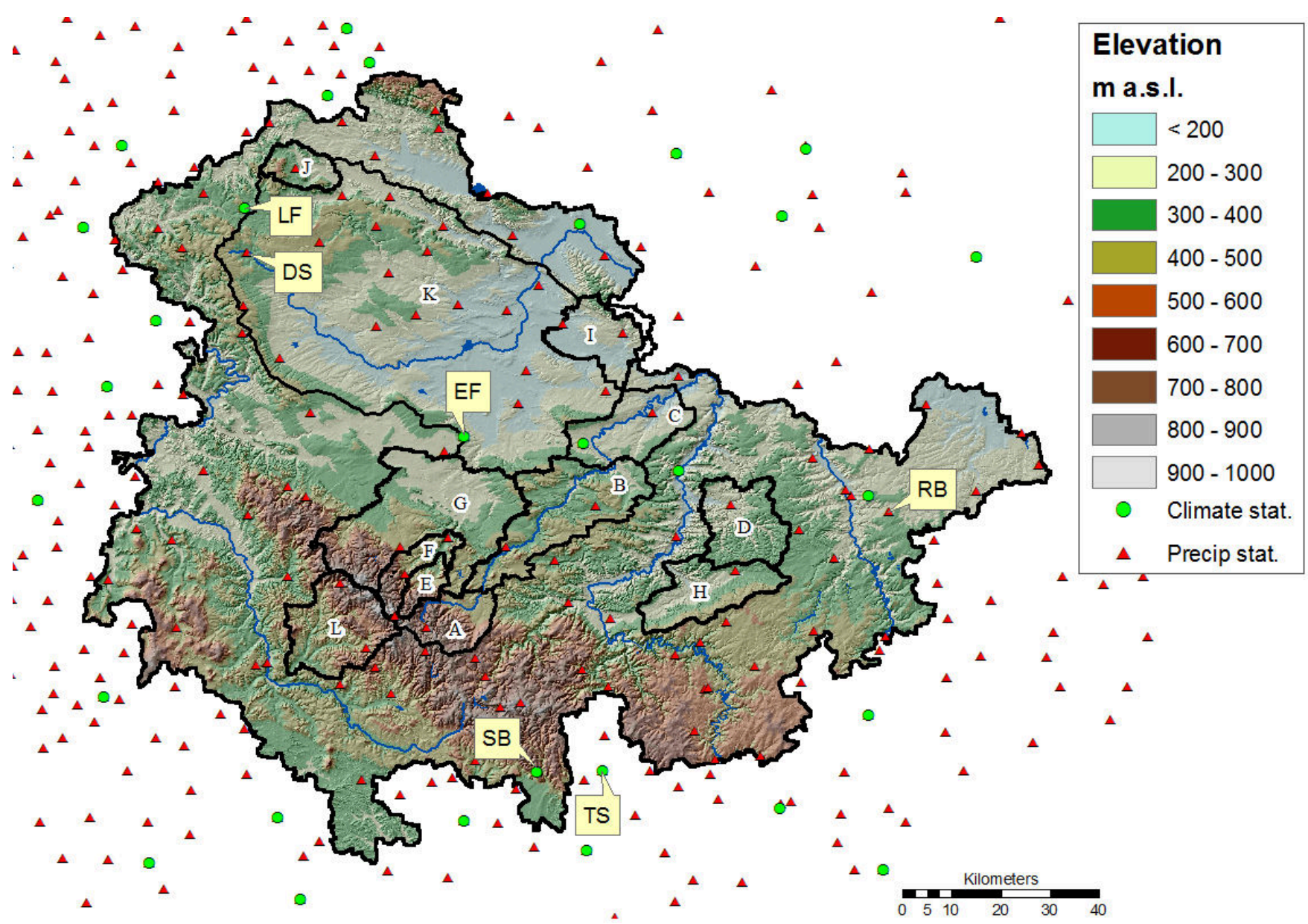

Fig. 1. The state Thuringia in Germany. The map shows the elevation above sea level and the location of climate and precipitation stations used in this study. Additionally, the subbasins used for calibration and validation marked with capital letters ((A): Ilm, gauge GräfinauAngstedt, (B): Ilm, gauge Mellingen, (C): Ilm, gauge Niedertrebra, (D): Roda, gauge Zöllnitz, (E): Zahme Gera, gauge Plaue, (F): Gera, gauge Arnstadt, (G): Gera, gauge Erfurt-Möbisburg, (H): Orla, gauge Freienorla, (I): Lossa, gauge Frohndorf, (J): Bode, gauge Bleicherode, (K): Unstrut, gauge Oldisleben, (L): Hasel, gauge Ellingshausen) and the climate and precipitation stations used for the WettReg validation (LF: Leinfelde, DS: Dingelstädt, EF: Erfurt, SB: Sonneberg, TS: Teuschnitz, RB: Ronneberg) are shown.

\subsection{Hydrological modelling}

The main objective of this study was to provide robust and reliable estimates of spatially distributed long-term mean runoff generation amounts for Thuringia. This quantification process was based on time series of precipitation and other climate elements, along with spatially distributed information about topography, land-use, soil types and hydrogeology. The estimated hydrological quantities were computed for past, recent and future conditions to provide a basis for the analysis of the potential long-term impact resulting from changing climate conditions. Beside the changes of mean annual quantities, seasonal distribution in terms of mean monthly estimates was of particular interest because: (1) projected climate data sets for the next 100 years indicate that the seasonal distribution of precipitation will change; whereas, the absolute annual amount will remain more or less the same (Christensen et al., 2007a); and (2) the projected increase in temperature can have an impact on parts of the seasonally variable hydrological process dynamics e.g. on snow accumulation and snow melt processes or on evapotranspiration.

\subsubsection{The model J2000g}

For this study, the J2000g was developed for historical simulations as well as for long-term hydrological projections. The development was guided by the following requirements: (1) continuous and distributed simulation of important hydrologic characteristics in monthly and daily time steps; (2) applicability to the entire area of Thuringia $\left(16172 \mathrm{~km}^{2}\right)$ but also to selected individual catchments within the state; (3) 
process oriented and spatially distributed modelling; and (4) robust predictive ability with a small number of calibration parameters.

The J2000g model was adapted from the $\mathbf{J} 2000$ model (Krause, 2001, 2002) within the JAMS modelling framework system (Kralisch and Krause, 2006) and can be categorised as a spatially distributed conceptual hydrological model. The primary goal of the modifications was to simplify many of the complex hydrological relationships within J2000, resulting in a significantly reduced number of calibration parameters while maintaining, as much as possible, the characteristics of the seasonal hydrological variability exhibited in catchments within Thuringia. The model J2000g requires spatially distributed information related to topography, landuse, soil type and hydrogeology to estimate specific attribute values for each modelling unit. A modelling unit can be a raster cell, a process unit, or a subbasin provided that spatial information is available for each attribute within each unit. J2000g also requires meteorological inputs (precipitation; minimum, average and maximum temperature; sunshine duration; wind speed and relative humidity) from one or more observation stations. The measured point data are transferred to each model unit using the spatial interpolation approach available in J2000 which is a combination of an optional elevation correction and an inverse-distance-weighting (IDW) interpolation. The elevation correction is made when the degree of correlation (calculated with a linear regression for each time step) between the variable values and the respective station elevation shows a coefficient of determination $\left(r^{2}\right)$ of equal or greater 0.7. In this case, the specificelevation dependent lapse rate, calculated from the regression, is used for the further processing along with IDW. If the $r^{2}$ is smaller than 0.7 then only IDW is used.

Next, net radiation is calculated from climate input data using the methods presented in Allen et al. (1998). Then potential evapotranspiration (PET) is computed according to the Penman-Monteith approach for various vegetation and land-use types.

Snow accumulation and snowmelt are simulated with a simple approach that estimates snow accumulation depending on a base temperature (Tbase) and snowmelt with a time-degree-factor $(T M F)$. During time periods when air temperature is above Tbase, precipitation and snow melt is transferred to the soil-water module. This module consists of a simple water storage with a capacity defined from the field capacity of the specific soil type within the respective modelling unit. For calibration purposes, the entire distribution of storage capacity values for all modelling units can be shifted up or down with a multiplier $(F C A)$ that has the same value for all modelling entities. Water stored in the soil-water storage can only be taken out through evapotranspiration. The actual evapotranspiration is determined by the saturation of the soilwater storage, the potential evapotranspiration and a calibration coefficient ETR. The ETR coefficient has a range between 0 and 1 and controls how potential evapotranspira- tion is reduced due to limited water availability. Runoff is generated only when the soil-water storage reaches saturation. The partitioning of generated runoff into direct runoff and percolation is based on the slope of the modelling unit and a calibration factor $L V D$ and the underlying hydrogeological unit. The percolation component is transferred to a groundwater storage component; outflow from this storage is simulated using a linear outflow routine in order to calculate baseflow with the help of a recession parameter $G W K$. The total streamflow at the outlet of a catchment results from the summation of the direct runoff and the baseflow components from each modelling unit.

The primary purpose of the $\mathrm{J} 2000 \mathrm{~g}$ model is to provide spatially distributed long-term estimates of the amount and seasonal distribution of the following hydrological quantities: actual evapotranspiration, runoff generation, and groundwater recharge. Because of this, the model is not fully suited to provide continuous and precise estimates of streamflow. For instance, runoff concentration processes are not explicitly considered and streamflow is computed by simply summing up the runoff components generated in each modelling unit of the catchment. Because of these simplifications, the model cannot account for losses and transformations during runoff concentration or for specific hydrological conditions such as streamflow and groundwater losses in karst regions or the influence of human activities.

\section{Results and discussion}

\subsection{Model application and calibration}

To provide spatially consistent input information for $\mathrm{J} 2000 \mathrm{~g}$, the state of Thuringia was partitioned into 221121 modelling units resulting from a GIS overlay of slope, aspect, land-use, soil type and hydrogeology. Slope and aspect were classified into five and three classes in advance. After the GIS overlay, the centroid coordinates, area, mean slope, most frequent aspect, soil type, land-use and hydrogeological type were extracted for each unit and transformed into a J2000g compliant data table. The soil type and the land-use information are correlated to specific tables during model initialisation to derive physical values for field capacity and vegetation-specific parameters such as the leaf-area-index.

Monthly values of observed climatological input data (temperature, precipitation, relative humidity, sunshine hours, and wind speed) from the meteorological stations shown in Fig. 1 were transferred to each modelling unit using data from the five closest stations.

Values of the six J2000g parameters (FCA, Tbase, TMF, $L V D, E T R$ and $G W K$ ) had to be estimated through a model calibration procedure. The calibration was done for a number of catchments within the state boundaries with sufficient streamflow observations. The selection of suitable catchments was complicated by the fact that J2000g does not 
explicitly recognize man-made influences on the hydrological processes and does not account for water losses in karst regions - both relevant factors for the streamflow amount in many of Thuringia's catchments. As a result, only catchments with minimal man-made influence and primarily impermeable bedrock conditions were selected for calibration.

Eight catchments were selected that met the above described constraints for calibration: Bode, Ilm, Wilde Gera, Gera, Zahme Gera, Roda, Orla, and Hasel. The contributing area of these catchments ranges between 13 and $320 \mathrm{~km}^{2}$ and are distributed throughout the state (see Fig. 1). For each catchment, values for the six model parameters were calibrated automatically using the Shuffled Complex Evolution University of Arizona (SCE-UA) method (Duan et al., 1994). SCE-UA adapts a selected number of model parameters in order to optimise a single objective function. The calibration was done with observed monthly climate values for the time period from November 1990 through October 1997 using the Nash-Sutcliffe efficiency (NSE) measure as objective function. The calibrated parameter values are shown together with the resulting NSE values in Table 1.

Column CV of Table 1 indicates that the degree of variability among the eight catchments varies for each parameter. The values for Thase vary the least for all catchments, probably because it is the most "physically based" and it is largely independent from other factors in the catchment. The low values of Tbase are caused by the monthly modelling time steps - Tbase represents the mean monthly temperature which has to be considerably below $0^{\circ} \mathrm{C}$ to store precipitation as snow for a longer period than one time step of one month.

The values for parameters $L V D$ and $G W K$ also indicate relatively low variability among the catchments. The NSE, however, was very sensitive to all three of these parameters and "good solutions" were only possible within a fairly narrow range of values. The remaining parameters $T M F, F C A$, and ETR exhibit considerably more variability among the catchments compared to the other three parameters. TMF was found to be related to Tbase, however, the NSE was not very sensitive to changes in $T M F$ and ETR which accounts for the wide range in values. The model response was sensitive to changes of parameter FCA only during the beginning of the modelling period until the soil storage was filled for the first time. After this point in time $F C A$ had only very little impact on the modelling results.

The NSE values for seven of the eight catchments were computed between 0.51 and 0.85 which demonstrates that $\mathrm{J} 2000 \mathrm{~g}$ simulates the observed streamflow reasonably well in the calibration period. Only the Roda catchment's streamflow could not be simulated with a comparable degree of accuracy. Because of the specific geological conditions in the Roda catchment, it was judged that the groundwater flow processes are governing the hydrological dynamics and that direct runoff is of less importance. With $\mathrm{J} 2000 \mathrm{~g}$ this specific conditions can only be reproduced to a limited degree be- cause of the simplified algorithm in this model for partitioning runoff into the two runoff components. Other possible reasons might include man-made influences (e.g. groundwater abstraction) which were not recognised in this study.

For the state-wide application of J2000g it was assumed that one "global" parameter set could be derived from the calibrated parameter values from the eight calibration catchments that would result in "reasonable" estimates for the entire state area. This global set was obtained from a sensitivity analysis of the model parameters carried out for the eight test catchments. With the sensitivity analysis reasonable values for specific parameters could be estimated based on their identifiability in different regions of Thuringia. The two snow parameters (Tbase, TMF) were sensitive in the higher elevation catchments whereas ETR, GWK and FCA could be better identified in the lowland catchments. The distribution parameter $L V D$ could be identified very well in all test catchments.

To test the global parameter set it was first used in each of the eight calibration catchments for the same time period used for the calibration. The resulting NSE value (NSE(gps)) for each catchment is also shown in Table 1. Although there was some reduction in model performance for each catchment, the range of NSE(gps) values (0.36 and 0.81) is very close to those obtained with the optimal parameter values for seven of the eight catchments. Only the NSE(gps) value of the Roda catchment shows again a very low value of only 0.22 .

\subsection{Model validation}

The application of the global parameter set in the eight calibration catchments (along with an uncertainty analysis not shown here) resulted in the conclusion that the $\mathrm{J} 2000 \mathrm{~g}$ model is fairly robust with an acceptable degree of certainty based upon model calibration. To test if the model is also producing reliable results for other time periods and other catchments, the global parameter set derived in the calibration catchments was used in twelve catchments for the longer period from November 1970 through October 2000. Figure 2 shows the observed and simulated runoff for the Unstrut catchment $(\mathrm{K}$ : in Fig. 1) which covers about one quarter of the entire state area.

The simulated streamflow values were aggregated to longterm mean monthly average values and compared to observed streamflow records. The results obtained in the catchments, delineated in Fig. 1, are shown in Fig. 3. The figure shows the observed (blue) and simulated (red) longterm mean monthly streamflow for each catchment along with box-whisker plots providing the statistical parameters of the 360 single monthly values of the simulated and observed time series. The plots indicate that $\mathrm{J} 2000 \mathrm{~g}$ is able to reproduce the historical 30-year long-term mean monthly runoff values quite well in nearly all catchments. The statistical information provided by the box-whisker plots indicates 
Table 1. Catchment areas, J2000g parameter values from SCE optimisation along with best Nash-Sutcliffe efficiency (NSE) achieved and the efficiencies obtained with the global parameter set (NSE(gps)) for the calibration catchments. The last column shows the coefficient of variation $(\mathrm{CV})$ of the calibrated parameter values. The values of this table were obtained with the calibration period from $11 / 1990$ through $10 / 1997$.

\begin{tabular}{lrrrrrrrrr}
\hline & Bode & Ilm & W. Gera & Gera & Z. Gera & Hasel & Roda & Orla & CV \\
\hline Ac $\left(\mathrm{km}^{2}\right)$ & 104 & 155 & 13 & 175 & 65 & 320 & 254 & 255 & - \\
\hline LVD & 2.80 & 1.54 & 1.00 & 1.00 & 1.00 & 1.00 & 1.00 & 1.00 & $46 \%$ \\
GWK & 4.09 & 3.38 & 2.32 & 2.96 & 3.24 & 4.14 & 8.07 & 6.76 & $43 \%$ \\
Tbase & -4.37 & -4.79 & -4.69 & -4.61 & -4.61 & -3.91 & -5.44 & -4.34 & $9 \%$ \\
TMF & 1.33 & 8.73 & 9.99 & 4.40 & 5.39 & 9.99 & 1.00 & 1.22 & $70 \%$ \\
FCA & 18.78 & 19.99 & 1.00 & 2.15 & 20.00 & 2.64 & 12.62 & 10.79 & $70 \%$ \\
ETR & 0.06 & 0.02 & 0.99 & 0.58 & 0.01 & 0.59 & 0.03 & 0.04 & $122 \%$ \\
\hline NSE & 0.85 & 0.75 & 0.65 & 0.84 & 0.75 & 0.80 & 0.30 & 0.51 & - \\
NSE(gps) & 0.75 & 0.73 & 0.55 & 0.81 & 0.77 & 0.77 & 0.22 & 0.36 & - \\
\hline
\end{tabular}

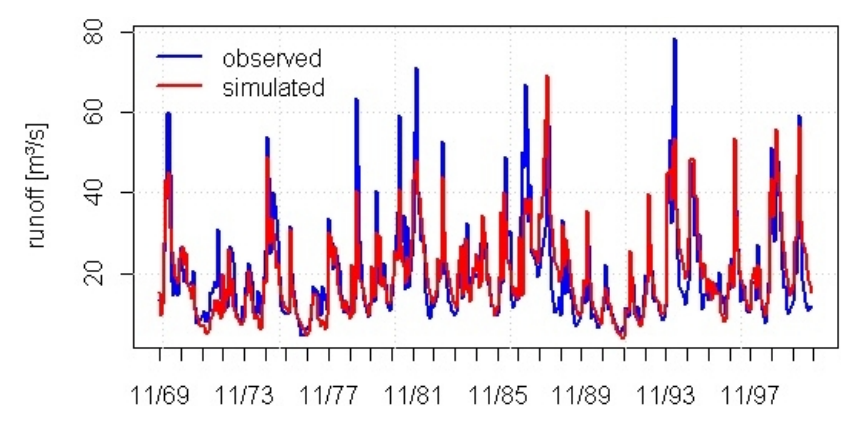

Fig. 2. Observed and simulated runoff of the river Unstrut obtained with the global parameter set.

that the model also is reproducing the runoff distribution, the mean values and the extremes reasonably well in most of the twelve catchments. It should be emphasised that these results were obtained with the global parameter set resulting from the calibration in eight catchments. The results for each catchment could undoubtedly be improved by catchmentspecific calibration.

\subsection{Simulation with climate projections}

The assessment of the climate change scenarios and their impact on the hydrological dynamics and balance was done by regionalisation, modelling and comparison of the reference period (time frame 1971-2000) and the projected future (time frame 2071-2100), based on observed climate values and the WettReg data for the SRES scenarios A2 and B1.

For this analysis, mean monthly values were computed from the daily WettReg realisations and further aggregated to 10 year mean average monthly values for each decade. These data were then used to drive the $\mathrm{J} 2000 \mathrm{~g}$ model using the averaged parameter set for all modelling units in Thuringia. The aggregation and averaging was done in order to reduce as much of the statistical randomness as possible, but to preserve the overall trend which was reported to be stable for mean decade values (UBA, 2007b).

For analysis of the $\mathrm{J} 2000 \mathrm{~g}$ spatially distributed output, the results of the 30 year period from 2071 to 2100 were aggregated to spatially distributed average values and visualised in maps. These results were compared with model results obtained with historical climate data of the period 1971 to 2000 . In order to analyse potential changes in the seasonal variability, seasonal averages or sums were computed for winter (December-February), spring (March-May), summer (JuneAugust) and fall (September-November) periods.

The computation and analyses were done for the important model inputs (i.e. temperature and precipitation) that govern the hydrological waterbalance; i.e., evapotranspiration, runoff generation and storage changes. These state variables were analysed in a spatially distributed manner to detect and quantify potential regional differences and dependencies.

\subsubsection{Temperature}

The long-term mean annual temperature indicated an increase of $+2.2^{\circ} \mathrm{C}$ for scenario A2 for 2071-2100 compared to 1971-2000. Scenario B1 indicates a smaller increase of $+1.8^{\circ} \mathrm{C}$. The temperature increase for distinct seasons was very different. The strongest increase occurred during the winter with +3.9 (A2) and $+3.3^{\circ} \mathrm{C}$ (B1). This is compared to the lowest increase in spring with $+0.7^{\circ} \mathrm{C}$. The assessment indicated that already after the first decades of the 21 century the average monthly temperature was continuously above $0^{\circ} \mathrm{C}$ throughout the year in Thuringia. The winter season showed a spatially differentiated warming pattern with a higher increase (up to $4.4^{\circ} \mathrm{C}$ for scenario A1) in the lowland areas and the eastern part and a lower increase in the higher mid-mountain regions. The temperature change in the other seasons indicated no distinct regional differences or patterns. The most likely impacts of the projected 

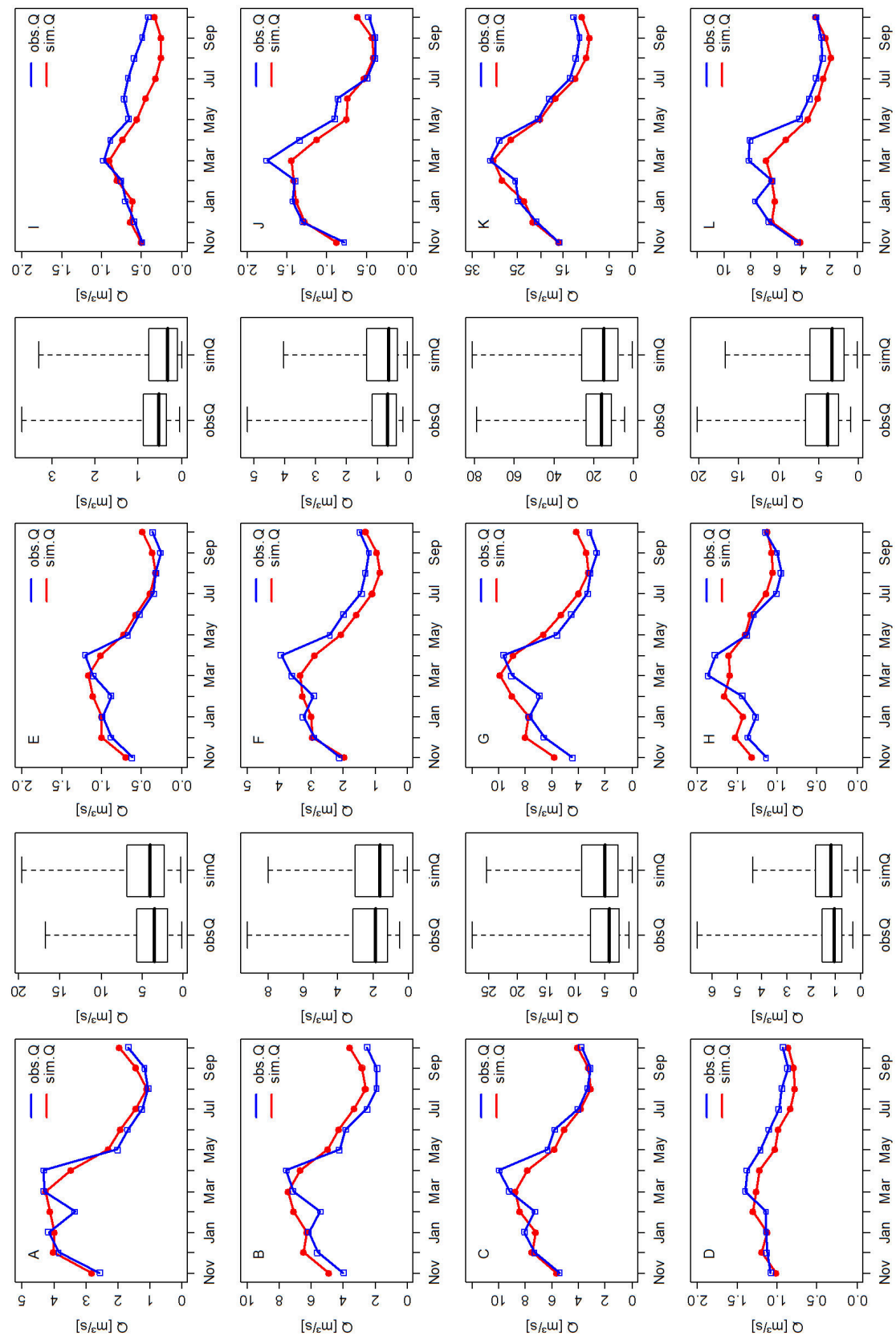

$[\mathrm{s} / \varepsilon \mathrm{\varepsilon}] \mathrm{O}$
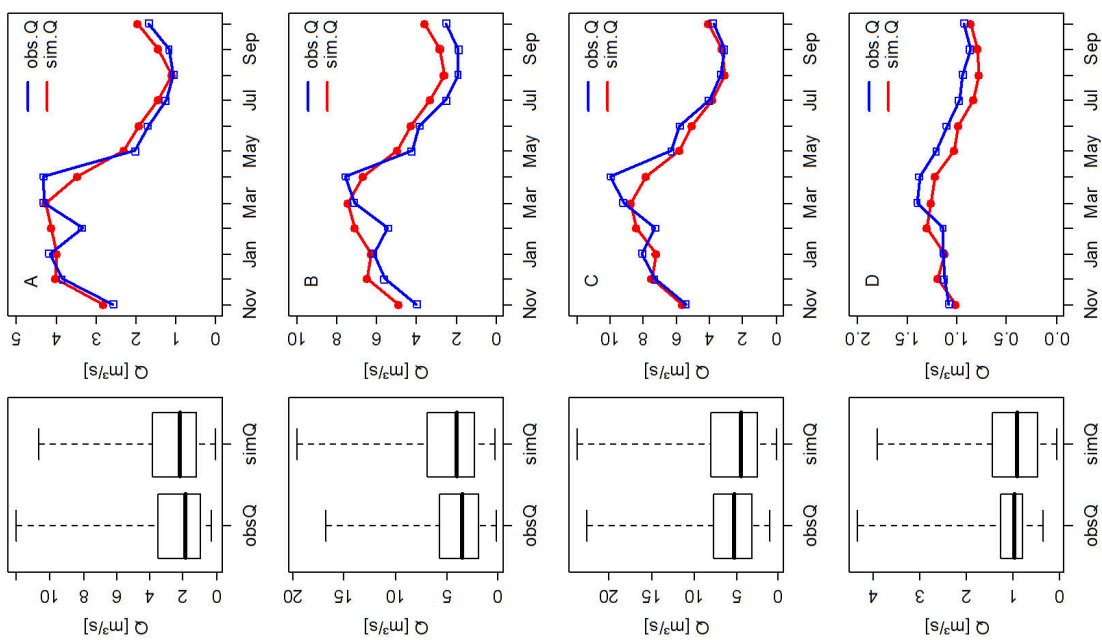

$[\mathrm{s} / \mathrm{s} u] \mathrm{O}$

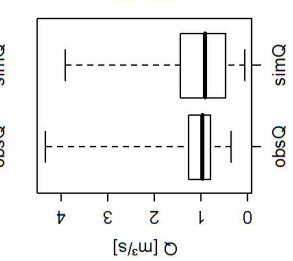

Fig. 3. Results of the validation of J2000g for 12 basins in Thuringia. ((A): Ilm, gauge Gräfinau-Angstedt, (B): Ilm, gauge Mellingen, (C): Ilm, gauge Niedertrebra, (D): Roda, gauge Zöllnitz, (E): Zahme Gera, gauge Plaue, (F): Gera, gauge Arnstadt, (G): Gera, gauge ErfurtMöbisburg, (H): Orla, gauge Freienorla, (I): Lossa, gauge Frohndorf, (J): Bode, gauge Bleicherode, (K): Unstrut, gauge Oldisleben, (L): Hasel, gauge Ellingshausen). The plots show the long-term mean monthly simulated (red line) and observed (blue line) streamflow of the period from 11/1970 through 10/2000. The box-whisker plots show the range, the median and the I. and III. quartile of the 360 ( 30 years with 12 months) simulated and observed monthly values. 
temperature increase on the hydrological balance are (1) an increase of potential evapotranspiration and (2) a decrease of snow accumulation. The latter can have significant impact on river runoff in the head-water catchments of the midmountain range as snow melt can be an important contribution to spring peak discharge in Thuringia.

\subsubsection{Precipitation}

Precipitation is the most important factor for hydrology. In recent years, the summer and winter precipitation amounts are nearly equal in Thuringia. The simulation with the WettReg data shows only a slight decrease of the cumulated annual precipitation of $-1.2 \%$ for scenario $\mathrm{A} 2$ and $-0.7 \%$ for scenario B1 from today to 2071-2100. Much more important is the projected change in the seasonal distribution of precipitation. For both scenarios, a strong increase of $+29.1 \%$ (A2) and $+22.7 \%$ (B1) of the winter precipitation was estimated. In spring, a slight increase of $+1.2 \%$ (A2) and $+2.9 \%$ (B1) occurred. In summer, large decreases of -14.3 and $-12.7 \%$ for scenario A2 and B1 were estimated. Similar reductions continue in the fall with values of $-17.2 \%$ and $-12.6 \%$. The spatial distribution of precipitation in the four seasons of the reference period and the future climate scenarios is shown in Fig. 4. The maps indicate that the precipitation increases in winter throughout the state, but the increase in localised midmountain regions in the south and west is relatively greater than in the lower elevation regions in the north and east. In spring, only minor differences in the spatial distribution pattern were computed. The plots for summer and fall show a decrease in precipitation. In these seasons the lowland areas are slightly more affected but also the precipitation in the higher areas decreases clearly.

\subsubsection{Evapotranspiration}

Potential evapotranspiration (PET) is primarily driven by energy supply whereas, actual evapotranspiration (AET) is also governed by water availability. From the change in temperature and the seasonal distribution of the precipitation a change in both PET and AET can be expected.

The J2000g model simulation results indicated a longterm statewide increase of AET by $+7.6 \%$ for scenario A2 and $+7.0 \%$ for scenario B1. The highest increase was computed in the summer season for both scenarios with values of $+16.8 \%$ (A2) and $+14.8 \%$ (B1). The maps in Fig. 5 indicate the seasonal annual patterns of AET for the 30 year reference period (1971-2000) and for the two scenarios. In winter, AET is low due to low temperature and only minimal changes occur due to higher temperature. In spring, an increase of AET occurs mainly in the western and southeastern part. In summer, the largest changes were computed that are impacting nearly the entire area of Thuringia. The spatial distribution indicates a larger increase in the higher elevation areas compared to the lowlands because of the greater water availability. In the lowlands a moderate increase of AET occurs despite the decreased rainfalls. The larger water amount consumed by the AET was taken out the soil water storage which leads to drier soils in the fall. In this season, a slight increase of AET in the higher areas was estimated, whereas AET decreases in the lowlands due to lower precipitation and a larger water deficit from the summer season.

\subsubsection{Runoff generation}

Runoff generation is computed by $\mathrm{J} 2000 \mathrm{~g}$ as the result of precipitation, actual evapotranspiration and potential changes in the two storages for soil moisture and groundwater. For spatially averaged and long-term mean runoff generation, a decrease of $-47 \mathrm{~mm}$ for the B1 scenario and $-55 \mathrm{~mm}$ for the A2 scenario was computed. In the winter season, a decrease of $-13 \mathrm{~mm}$ (A2) and $-9 \mathrm{~mm}$ (B1) was calculated as the statewide mean. The maps in Fig. 6 indicate that this decrease is very heterogeneously distributed throughout the area. For the mid-mountain region in the north-west, the south, and in particular in the south-west part of Thuringia larger increases were estimated, due to higher rainfalls. For the lowlands in the central and northern parts, decreases in runoff generation were simulated. In spring, slight decreases of $-7 \mathrm{~mm}$ (A2) and $-4 \mathrm{~mm}$ (B1) were computed as a result from a mixture of increasing runoff generation in the higher areas and a decrease in the lower regions. A slight decrease for the entire area of Thuringia was estimated for the summer season. This estimated overall decrease is only moderate, because the runoff generation in Thuringia is in general very low during summer. Because of the general low runoff generation, the reduction of precipitation and the increase in AET in summer does not have a large impact on runoff generation, but the higher deficit of water leads to a stronger reduction of the water content in the soils as well as in the groundwater storage. Because of the higher deficit in summer, decreases of $-33 \mathrm{~mm}$ (A2) and $-35 \mathrm{~mm}$ (B1) were calculated in the fall for the entire area. The spatial distribution in Fig. 6 indicates that the higher elevation regions are experiencing the largest decrease primarily because of a large increase in AET and a decrease in precipitation. In general, both scenarios indicate the same spatial and temporal patterns; however the amplitude of the A2 scenario is slightly higher than that of B1.

\subsection{Considerations about uncertainty}

The study presented here contains a large amount of uncertainty due to various sources. In this section, we will look at some of these sources in a descriptive and semi-qualitative way, as precise quantification is not always possible.

First of all it should be noted that the results produced by climate models for the future should not be considered as precise predictions as uncertainty in predictions of 

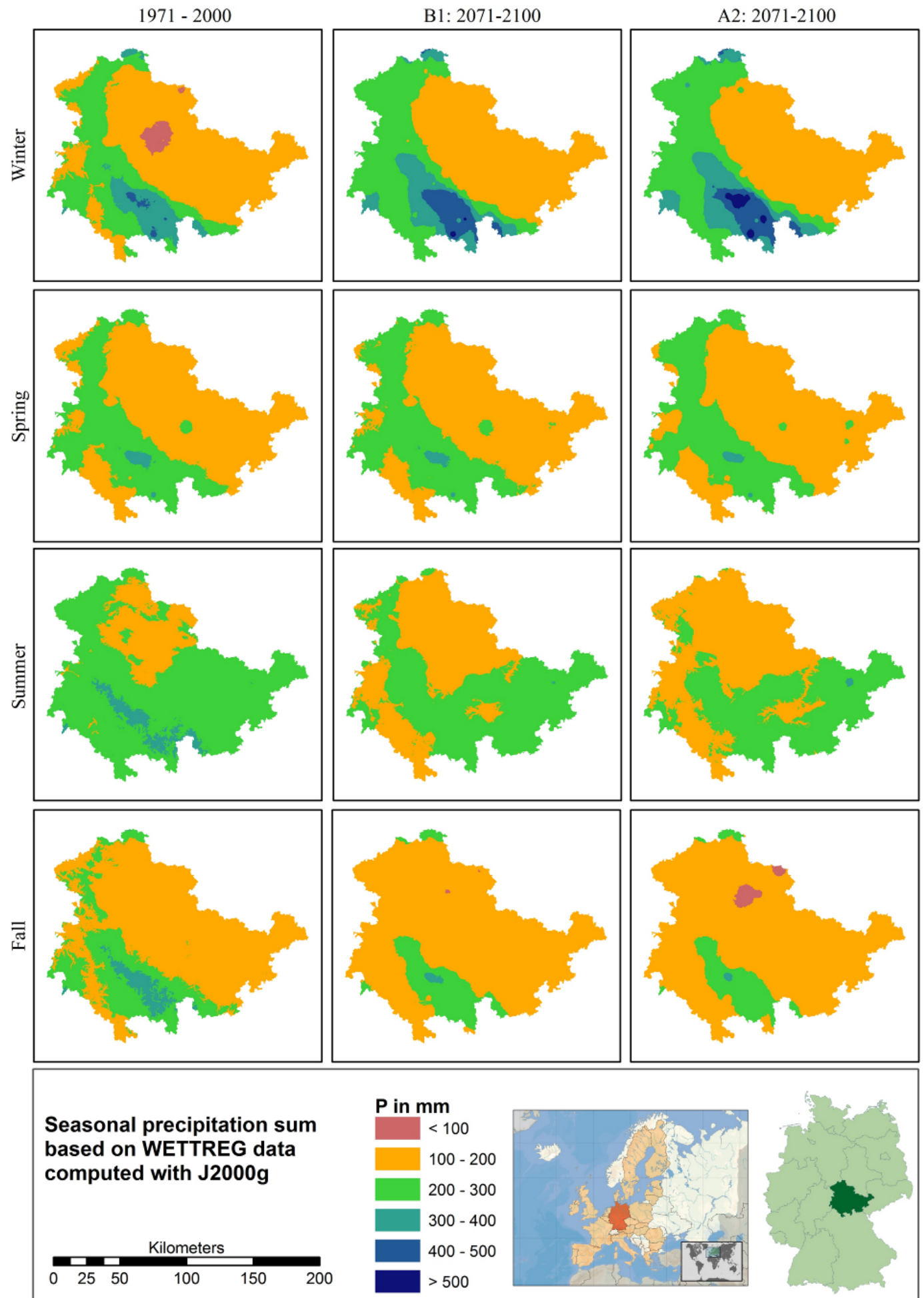

Fig. 4. Spatial distribution of cumulated seasonal precipitation. First column shows the regionalized values of 1971-2000, second and third column the regionalized values for the B1 and A2 scenario for the time frame 2071-2100. 

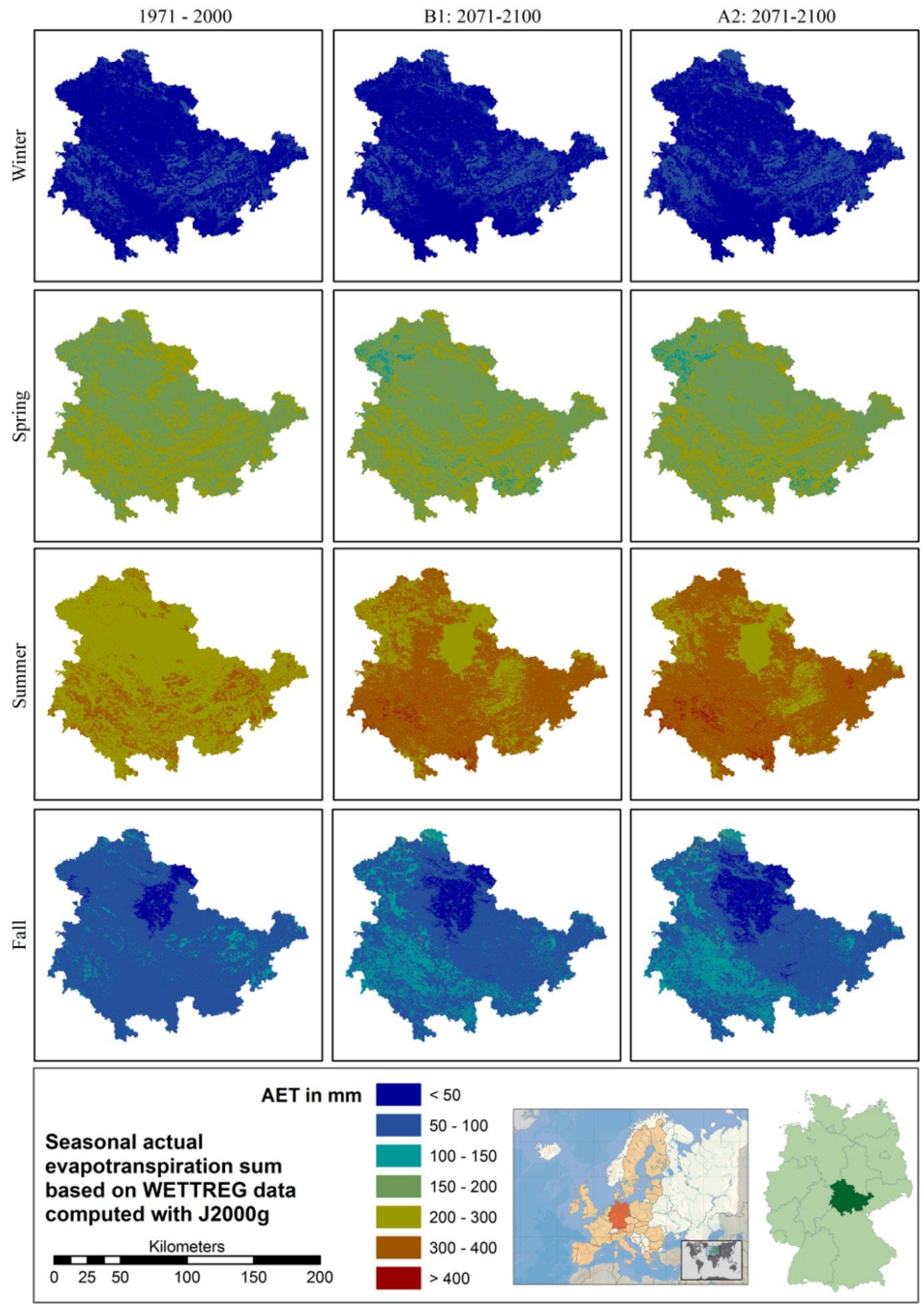

Fig. 5. Spatial distribution of seasonal actual evapotranspiration sums. First column shows the simulated values of 1971-2000, second and third column the simulated values for the B1 and A2 scenario for the time frame 2071-2100. 

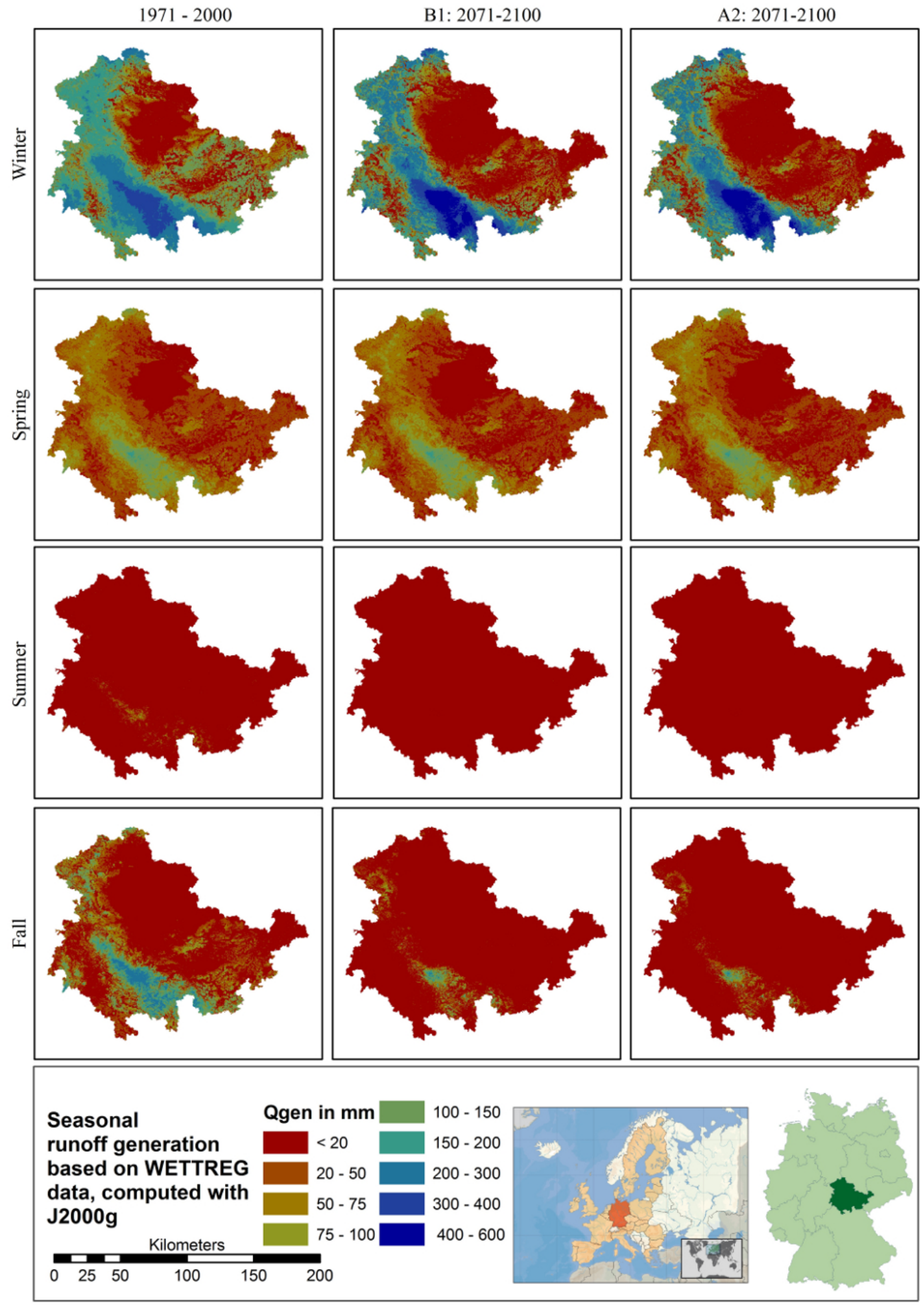

Fig. 6. Spatial distribution of seasonal runoff generation sums. First column shows the simulated values of 1971-2000, second and third column the simulated values for the B1 and A2 scenario for the time frame 2071-2100. 
anthropogenic climate change arises at all stages of the modelling process (Meehl et al., 2007). Rather, they should be considered as projections computed on the basis of specific assumptions about the global development over the next 100 years. Various factors with an uncertain future development are involved in the evolution and change of climate. This implicates that the climate change scenarios are only more or less likely trends, based on the current knowledge and perception (UBA, 2007a).

The results of climate models that are used to calculate the scenarios are also uncertain to some degree. Even if the GCMs are continuously enhanced, does multi-model ensemble simulation produce more reliable results than every single model can (Randall et al., 2007). IPCC accounts for this higher single model uncertainty by the use of the results of about 23 models to base their assumptions of projected climate change on.

For regional studies, like the one presented here, such an ensemble projection is not possible because only a limited number of regional models exist. The downscaling approaches used to derive such regional models tend to introduce additional uncertainty. The validation of the statistical downscaling approach WettReg indicated that precipitation and temperature were reproduced fairly well for the historical reference period 1971-2000. However, it is not possible to quantify the quality of the projections of future climate for the assumed scenarios. Because the downscaling approach is based on simulation results of the global model ECHAM5, any uncertainty of the global model is transferred over into the regional one (Zebisch et al., 2005).

Another source of uncertainty of the WettReg climate data set in Thuringia involves the relative low number of climate stations (see Fig. 1) which provide data for the state area. Only seven of the 33 climate stations used for this study were located within the Thuringia state boundaries. The spatial interpolation of the climate values temperature, relative humidity, wind speed and sunshine duration was based upon limited site records that add uncertainty relative to the spatial representation and variability. This is particularly true for the mid-mountain region. Fortunately, precipitation is represented by much more stations. Around 100 of the 300 stations were located inside the state boundaries and are distributed sufficiently in space throughout the area.

The hydrological modelling using J2000g also contributes uncertainty, because any simplified model cannot integrate all hydrological processes in every aspect. The simple concept on the other hand results in a limited number of calibration parameters which makes the modelling and the parameter estimation a transparent process. Validation in a number of catchments indicated that the long-term simulation results were in an acceptable range that allows the use of the model for long-term analyses as presented here. An evaluation of the uncertainty and parameter sensitivity of $\mathrm{J} 2000 \mathrm{~g}$ which is not shown in this paper indicated that the calibrated model was able to reproduce historical hydrological conditions in a number of catchments to an acceptable degree. The analysis indicated that the uncertainty resulting from single parameter variations was relatively low compared to the influence of climate input data on the model response.

There are other factors which might be relevant for projections and trends simulated over the next 100 years. First, the hydrological model assumes that the areal landuse/landcover remains constant from 2000 to 2100 without any change. It is very likely that the projected climate change will have impact on land-use and landcover that in turn will have impact on the hydrological dynamics. The same is true for the soil physical properties which can also change in the next 100 years because of changing climate and different land-use. Consideration of such changes might result in more realistic model projections. However, the assumptions themselves about such changes would again introduce a hard to quantify degree of uncertainty.

The large degrees of uncertainty in the different parts of the methodology limit the results of this study to some extent. Unfortunately, it is not possible to quantify all different sources of this uncertainty precisely. Anyway, assuming that the downscaled input data from the climate model indicates a probable trend, it can be expected that the time trends computed using the methodology and tools from this study would produce a similar likely projection of future hydrological conditions throughout Thuringia.

\section{Summary, conclusion and outlook}

In this study the IPCC emission scenarios A2 and B1 and their regional impact on temperature, precipitation, evapotranspiration and runoff generation in Thuringia for the 2071-2100 time frame were analysed. The analysis indicated time trends which can be summarised as follows:

The predicted temperature increase due to climate change will have impact on other climatological, meteorological and hydrological processes. Both scenarios indicated an increase in the annual temperature that would be greater in scenario A2. In terms of temporal distribution, the winter months would be characterised with temperature increases of up to $3-4^{\circ} \mathrm{C}$.

Annual precipitation amounts showed only small changes if considered for the entire state area, but distinctively changing temporal and spatial distributions of precipitation were projected. The projected precipitation change would result in more rainfall during the winter months and less precipitation during summer and fall. During winter, the higher elevation areas would experience the strongest increase; whereas, the lowlands would be less affected.

The increase of the temperature and the change in precipitation will have impact on the actual evapotranspiration (AET). An increase in AET during summer and fall was computed; whereas, the AET rates in winter and spring will not change as much. The increase would mainly occur in the 
higher elevation areas, because in these regions the water necessary for evapotranspiration tends to be more available. In the lowlands, only a slight increase of AET was computed, due to limited water availability.

The distributed model results presented in this study emphasises the importance of high resolution input data for regional impact analysis. Only with such data, the spatial and temporal variable distribution of precipitation, evapotranspiration and runoff generation can be reproduced and simulated sufficiently.

The changing climate conditions will have impact on the runoff generation and streamflows in Thuringia. The higher precipitation rates in the mid-mountain regions in winter will lead to an increased runoff generation and higher streamflows. Because of the expected rise in temperature it is very likely that longer lasting seasonal snow covers would occur less frequent or would vanish completely in Thuringia. For the lowland regions a distinct decrease in runoff generation was simulated, resulting from the lower precipitation and slightly higher actual evapotranspiration amounts. In particular, during summer and fall, Thuringia is already a relative dry region in Germany, which would be even more intensified due to the projected future climate changes. The reduced runoff generation would not only have impact on the streamflow, as indicated for the lower parts of the river Ilm catchment. Moreover, it can have major influence on the spatial water availability, soil-moisture balance and groundwater recharge. Such influences can have negative future effects on the agricultural production in the lower regions of Thuringia.

It is understood that this study and the anticipated trends include a large degree of uncertainty that unfortunately is not easy to quantify in total. The uncertainty introduced from various sources includes the climate model, the downscaling method, the hydrological model and associated input data, but also the climate scenarios and the assumptions the scenarios are based on. Besides the changing weather conditions due to projected climate change, there are other additional side effects, e.g., on the land-use or soil physical properties, that also can impact the hydrological processes but that are very hard to quantify with complete certainty. The validation of the downscaling method WettReg and the validation and uncertainty analysis of the hydrological model J2000g confirmed that these tools are able to reproduce long-term historical climate and hydrological conditions with an acceptable level of confidence.

Assuming that the overall time trend and directions of the projected climate development and of the findings estimated in this study are correct, projected climate change would have major impact on the hydrological dynamics and water availability in Thuringia. The projected spatially distributed water availability in summer and fall will be less than is presently available, particularly for the lowland regions. These regions are largely used for agriculture, which relies on sufficient water availability for crop growth that might be limited in the future. The projected increase of precipitation during the winter in the higher elevation regions would lead to an increase of streamflow, because in these regions soil moisture and groundwater levels are already relative high. Even if extreme values were not considered directly in this study, it is very likely that the increase in runoff would also result in an increase of flood frequencies.

The present study could only address some of the research questions that could be tackled for such a complex problem. Further investigation should include an analysis of the projected climate time series in terms of extreme values. Such an analysis should investigate the data sets for changing frequencies and recurrence of precipitation extremes and could simulate their impact on runoff generation and streamflows using the $\mathrm{J} 2000 \mathrm{~g}$ model. For this purpose, the model should be applied with a higher temporal resolution than the monthly time steps of this study. Preliminary tests indicated that higher temporal resolution (i.e. daily time steps) would result in a better representation of snow accumulation and melt processes and would allow the separation of three runoff components (surface runoff, interflow, baseflow).

The large amount of data of the statistical downscaling approach WettReg (20 realisations for each day of the time period 2000-2100) would enable ensemble simulations of the hydrological quantities. Such modelling would result in a very large amount of data values and would require a high degree of computing power. The advantage would be a better assessment of the uncertainty introduced by the combined use of the projected data and the hydrological simulation. For a better quantification of the WettReg methodology and the downscaled projected climate data a comparison with other downscaled data sets could provide more insights.

Acknowledgements. The authors thank the organisers of the Kiel-Workshop on "Großskalige Modellierung in der Hydrologie" for the excellent organisation. Additional thanks goes to the Thuringian Environment Agency (TLUG) for funding, to T. D. Steele, H. Bormann, J. C. Ascough II and D. P. Boyle for valuable advises and proof reading and to $\mathrm{M}$. Wegehenkel and one anonymous reviewer for constructive and helpful critics and suggestions.

Edited by: B. Schmalz, K. Bieger, and N. Fohrer

Reviewed by: M. Wegehenkel and another anonymous referee

\section{References}

Allen, R. G., Pereira, L., Raes, D., and Smith, M.: Crop evapotranspiration: Guidelines for computing crop water requirements, 56, FAO Irrigation and Drainage Paper, 1998.

Arnell, N. W.: Effects of IPCC SRES Emissions Scenarios on River Runoff: A Global Perspective, Hydrol. Earth Syst. Sci., 7(5), 619-641, 2003.

Bronstert, A., Kolokotronis, V., Schwandt, D., and Straub, H.: Vergleich und hydrologische Wertung regionaler Klimaszenarien für 
Süddeutschland, Hydrologie und Wasserwirtschaft, 50, 270-287, 2006.

Christensen, J., Hewitson, B., Busuioc, A., Chen, A., Gao, X., Held, I., Jones, R., Kolli, R., Kwon, W.-T., Laprise, R., Rueda, V. M., Mearns, L., Menéndez, C., Räisänen, J., Rinke, A., Sarr, A., and Whetton, P.: Climate Change 2007: The Physical Science Basis. Contribution of Working Group I to the Fourth Assessment Report of the Intergovernmental Panel on Climate Change, chap. Regional Climate Projections, Cambridge University Press, Cambridge, UK and New York, NY, USA, 847-940, 2007a.

Christensen, J. H., Carter, T., Rummukainen, M., and Amanatidis, G.: Evaluating the performance and utility of regional climate models: the PRUDENCE project, Clim. Change, 81, 1-6, 2007b.

Covey, C., AchutaRao, K. M., Cubasch, U., Jones, P., Lambert, S. J., Mann, M. E., Phillips, T. J., and Taylor, K. E.: An Overview of Results from the Coupled Model Intercomparison Project (CMIP), Global Planet. Change, 37, 103-133, 2003.

Deque, M., Rowell, D. P., Lüthi, D., Giorgi, F., Christensen, J. H., Rockel, B., Jacob, D., Kjellström, E., de Castro, M., and van den Hurk, B.: An intercomparison of regional climate simulations for Europe: assessing uncertainties in model projections, Clim. Change, 81, 53-70, 2007.

Duan, Q., Sorooshian, S., and Gupta, V. K.: Optimal Use of the SCE-UA Global Optimization Method for Calibrating Catchment Models, J. Hydrol., 158, 265-284, 1994.

Ekström, M., Hingray, B., Mezghani, A., and Jones, P.: Regional climate model data used within the SWURVE project 2: addressing uncertainty in regional climate model data for five European case study areas, Hydrol. Earth Syst. Sci., 11(1), 1085-1096, 2007

Enke, W. and Spekat, A.: Downscaling climate model outputs into local and regional weather elements by classification and regression, Clim. Res., 8, 195-207, 1997.

Enke, W., Deutschländer, T., Schneider, F., and Küchler, W.: Results of five regional climate studies applying a weather pattern based downscaling method to ECHAM4 climate simulation, Meteorologische Zeitschrift, 14, 247-257(11), 2005a.

Enke, W., Schneider, F., and Deutschländer, T.: A novel scheme to derive optimized circulation pattern classifications for downscaling and forecast purposes, Theor. Appl. Climatol., 82, 51-63, 2005b.

Jacob, D., Bärring, L., Christensen, O. B., Christensen, J. H., de Castro, M., Deque, M., Giorgi, F., Hagemann, S., Hirschi, M., Jones, R., Kjellström, E., Lendrink, G., Rockel, B., Sanchez, E., Schär, C., Seneviratne, S. I., Somot, S., van Ulden, A., and van den Hurk, B.: An inter-comparison of regional climate models for Europe: model performance in present-day climate, Clim. Change, 81, 31-52, 2007.

Kralisch, S. and Krause, P.: JAMS - A Framework for Natural Resource Model Development and Application, in: 7th International Conference on Hydroinformatics, HIC, Nice, France, 2006.

Krause, P.: Das hydrologische Modellsystem J2000: Beschreibung und Anwendung in groen Flueinzugsgebieten, Schriften des Forschungszentrum Jülich: Reihe Umwelt/Environment, Band 29, 2001.

Krause, P.: Quantifying the Impact of Land Use Changes on the Water Balance of Large Catchments using the J2000 Model, Phys.
Chem. Earth, 27, 663-673, 2002.

Kunstmann, H., Schneider, K., Forkel, R., and Knoche, R.: Impact analysis of climate change for an Alpine catchment using high resolution dynamic downscaling of ECHAM4 time slices, Hydrol. Earth Syst. Sci., 8(6), 1030-1044, 2004.

Leander, R. and Buishand, T. A.: Resampling or regional climate model output for the simulation of extreme river floods, J. Hydrol., 332, 487-496, 2007.

Lehner, B., Döll, P., Alcamo, J., Henrichs, T., and Kaspar, F.: Estimating the impact of global change on flood and drought risks in Europe: A continental integrated analysis, Clim. Change, 75, 273-299, 2006.

McAvaney, B. J., Covey, C., Joussaume, J., Kattsov, V., Kitoh, A., Ogana, W., Pitman, A. J., Weaver, A. J., Wood, R. A., and Zhao, Z.-C.: Climate Change 2001. The Scientific Basis. Contribution of Working Group I to the Third Assessment Report of the Intergovernmental Panel on Climate Change, chap. Model evaluation, 471-523, Cambridge University Press, 2001.

Meehl, G. A., Stocker, T. F., Collins, W. D., Friedlingstein, P., Gaye, A. T., Gregory, J. M., Kitoh, A., Knutti, R., Murphy, J. M., Noda, A., Raper, S. C. B., Watterson, I. G., Weaver, A. J., and Zhao, Z.C.: Climate Change 2007. The Physical Science Basis of Climate Change. Contributions of Working Group I to the Fourth Assessment Report of the Intergovernmental Panel on Climate Change, chap. Global Climate Projections, 740-844, Cambridge University Press, 2007.

Menzel, L. and Bürger, G.: Climate Change Scenarios and Runoff Response in the Mulde Catchment (Southern Elbe, Germany), J. Hydrol., 267, 53-64, 2002.

Murphy, J.: An evaluation of statistical and dynamical techniques for downscaling local climate, J. Climate, 12, 2256-2284, 1999.

Nakicenovic, N., Alcamo, J., Davis, G., de Vries, B., Fenhann, J., Gaffin, S., Gregory, K., Grübler, A., Jung, T. Y., Kram, T., Rovere, E. L. L., Michaelis, L., Mori, S., Morita, T., Pepper, W., Pitcher, H., Price, L., Riahi, K., Roehrl, A., Rogner, H.-H., Sankovski, A., Schlesinger, M., Shukla, P., Smith, S., Swart, R., van Rooijen, S., Victor, N., and Dadi, Z.: Special Report on Emissions Scenarios, Intergovernmental panel on climate change, 2000.

Orlowsky, B., Gerstengarbe, F.-W., and Werner, P. C.: A resampling scheme for regional climate simulations and its performance compared to a dynamical RCM, Theor. Appl. Climatol., 2007.

Randall, D. A., Wood, R. A., Bony, S., Colman, R., Fichefet, R., Fyfe, J., Kattsov, V., Pitman, A., Shukla, J., Sinivasan, J., Stouffer, R. J., Sumi, A., and Taylor, K. E.: Climate Change 2007. The Physical Science Basis of Climate Change. Contributions of Working Group I to the Fourth Assessment Report of the Intergovernmental Panel on Climate Change, chap. Climate Models and their Evaluations, 589-662, Cambridge University Press, 2007.

Roeckner, E., Baeuml, G., Bonaventura, L., Brokopf, R., Esch, M., Giorgetta, M., Hagemann, S., Kirchner, I., Kornblueh, L., Manzini, E., Rhodin, A., Schlese, U., Schulzweida, U., and Tompkins, A.: The Atmospheric General Circulation Model ECHAM5 - Part 1: Model Description. MPI-Berichte Bd. 349 - Hamburg, Tech. rep., Max-Planck-Institute for Meteorology, Hamburg, Germany, 2003.

Thodsen, H.: The influence of climate change on stream flow in 
Danish rivers, J. Hydrol., 333, 226-238, 2007.

UBA: Neue Ergebnisse zu regionalen Klimaänderungen. Das statistische Regionalisierungsmodell WETTREG, Tech. rep., Umweltbundesamt, 2007a.

UBA: Neuentwicklung von regional aufgelösten Wetterlagen für Deutschland und Bereitstellung regionaler Klimaszenarios auf der Basis von globalen Klimasimulationen mit dem Regionalisierungsmodell WETTREG auf Basis von globalen Klimasimulationen mit ECHAM5/MPI-OM T63L31 2010 bis 2100 für die SRESSzenarios B1, A1B und A2, Tech. rep., UBA, 2007b.

van Ulden, A. P. and van Oldenborgh, G. J.: Large-scale atmospheric circulation biases and changes in global climate model simulations and their importance for climate change in Central Europe, Atmos. Chem. Phys., 6, 863-881, 2006,

http://www.atmos-chem-phys.net/6/863/2006/.
Wilby, R. L. and Wigley, T. M. L.: Downscaling general circulation model output: a review of methods and limitations, Progress in Physical Geograpyhy, 21(4), 530-548, 1997.

Wilks, D.: Interannual variability and extrem-value characteristics of several stochastic daily precipitation models, Water Resour. Res., 34, 2995-3008, 1999.

Zebisch, M., Grothmann, T., Schröter, D., Hasse, C., Fritsch, U., and Cramer, W.: Climate Change in Germany - Vulnerability and Adaptation of Climate sensitive Sectors, UBA, Germany, 2005. 